\title{
Models and Areas for CS Education Research
}

Mike Clancy ${ }^{1}$, John Stasko ${ }^{2}$, Mark Guzdial ${ }^{3}$, Sally Fincher ${ }^{4}$, and Nell Dale ${ }^{5}$ ${ }^{1}$ Computer Science Division, University of California, Berkeley, ${ }^{2}$ College of Computing, Georgia Institute of Technology, ${ }^{3}$ College of Computing, Georgia Institute of Technology, ${ }^{4}$ Computing Laboratory, University of Kent, and ${ }^{5}$ Computer Science Department, University of Texas, Austin, USA

\begin{abstract}
A suite of five short papers which aim to provide an overview of several aspects of CS education research, especially: previous work of interest, current projects and results; suggestions and resources for getting started in CS education research, and for forming and entering research communities.
\end{abstract}

\section{INTRODUCTION (MICHAEL CLANCY)}

The five papers in this section all arose from a panel organized for the SIGCSE Technical Symposium on Computer Science (CS) Education in Charlotte, NC in February, 2001. The aim of the panel was to alert attendees to several aspects of CS education research:

- previous work of interest;

- current projects and results;

- suggestions and resources for getting started and for forming and entering research communities.

The first two papers report research currently being conducted at Georgia Tech. John Stasko has for many years been exploring animation - dynamic visualization - as a tool for teaching algorithms and data structures. He briefly summarizes the evolution of research in this area, then reports a recent study that suggests the value of animations as motivators for in-depth study of complex algorithms. Finally, he suggests several avenues for tool builders,

Correspondence: Sally Fincher, Computing Laboratory, University of Kent at Canterbury, Canterbury, Kent CT2 7NF, UK. E-mail: s.a.fincher@ukc.ac.uk 
animation designers, and education researchers to collaborate on further work in this area.

Mark Guzdial, in contrast, has focused on ways to teach design. He describes the effects of a bottom-up approach to teaching the Model-ViewController (MVC) design pattern; having students first design interfaces without MVC, then apply MVC to improve their designs seems to have significantly improved their understanding of this pattern. Mark also reports experience with an on-line library of case studies of object-oriented design. He notes the benefits that surveys, interviews, and focus groups provided for his research into how students used the library, and suggests qualitative observation and data collection as valuable not just for researchers but for teachers as well.

My own contribution follows next. It surveys several older explorations of misconceptions and mistaken attitudes that students acquire. Such research, again mostly qualitative, provides great opportunities for collaboration between teachers and researchers. Identification of common misconceptions can guide teachers to help students counter or avoid them. Alert teachers can help provide systematic explanations of the nature and cause of student errors.

Nell Dale, in the next paper, describes the 11-year evolution of the CS Education Group at the University of Texas in Austin. The group started via a seminar whose main activity was reviewing the ACM and IEEE curriculum documents. The group meetings developed into a forum for review of outside research, presentation and support of internal work, discussion of applications of research to teaching, and several other activities. The group partners computer scientists with education specialists; participants include faculty and students, both at the University of Texas and at neighboring institutions.

Finally, Sally Fincher addresses the problem of finding a community outside one's local institution. She maps the various organizations supporting CS education research, conferences at which such work is presented, and ways to decide which community best matches one's own interests.

A thread connecting all these papers is collaboration. We face not only the ongoing unsolved problems of teaching core material but also the challenges of incorporating new technology and new techniques into our courses. Only by combining efforts of developers, practitioners, teachers, and researchers can we meet these challenges effectively. We hope these papers will encourage the readers to seek out partnerships and start participating. 


\section{EVALUATING ALGORITHM ANIMATIONS AS LEARNING AIDS (JOHN STASKO)}

My involvement with computer science education research has been focused on algorithm animation, using dynamic visualizations to help students learn about computer algorithms and data structures (Stasko, Domingue, Brown, \& Price, 1998). Understanding algorithms and data structures is one of the most important and challenging tasks for students, largely due to the abstract nature of these topics. I have developed a number of systems (XTango, Polka, Samba) that help both instructors and students build informative animations that illustrate the fundamental data structures and operations of algorithms. Much of this research is typical of early work in algorithm animation in being technology-centric i.e., the focus of the research was to build more powerful and more flexible system infrastructures for designing a variety of styles of algorithm animations.

This type of research is necessary in a new area in order to provide the subjects to be further studied. In algorithm animation, it was necessary to create both systems and animations that would illustrate a variety of approaches for visualizing an algorithm and communicating about how it works.

As the area has matured over the past 5-8 years, a shift in the research focus has occurred. More recent algorithm animation research has turned toward evaluating animations as learning aids and identifying if, how, and why animations can help students learn algorithms better. This shift from a technology-centric research thrust to a pedagogy-centric thrust shows the maturation of the field and reflects educators valid concerns about the utility and value of algorithm animations.

The intuition of instructors has been that animations and visualizations should help students learn about algorithms. After all, how many teachers discuss algorithms without drawing pictures? Furthermore, animation provides the ability to illustrate the dynamics of an algorithm and how it evolves over time. Unfortunately, this intuition has not always been borne out by the experimental studies examining the effects of algorithm animations on learning. The few existing empirical studies have shown rather mixed results. Some have yielded significant learning results in particular cases while others have found no significant learning benefit (Hundhausen, Douglas, \& Stasko, 2001).

These findings should not be surprising, however. Conducting careful experiments in this area is exceptionally difficult for a wide variety of reasons. 
Researchers must worry about animation quality, student demographics, equal treatment of students and conditions, simply getting enough participants, how to measure learning, etc. Perhaps most important, achieving a statistically significant result is quite difficult in a learning/education situation without having large numbers of student participants in the study.

To address these challenges, some colleagues and I recently conducted a study in which we altered the learning scenario from the style used in the majority of prior algorithm animation experiments (Kehoe, Stasko, \& Taylor, 2001). Rather than using an exam-style situation of an initial learning period followed by a timed final exam, we shifted to more of a homework-style learning situation. Learners were provided with both the instructional materials and the questions to be answered at the start of a session, and they were given unlimited time to answer those questions. One group received a textual description of the algorithm to be learned, supplemented by figures and diagrams. The other group instead received the same textual description along with a series of animations of the algorithm's key operations.

Participants in the study were 12 graduate students (split into two groups, each of six), and they were learning about the binomial heap data structure, a relatively challenging structure with a set of complex operations. The students were given 23 questions to answer. These questions covered a variety of styles, ranging from factual questions about attributes of the binomial heap to more procedural questions requiring the students to be able to carry out its operations.

We found a statistically significant learning effect for the students in the group seeing the animations, 20.5 vs. 16 correct answers, $p<0.03$. But perhaps more importantly, we noticed a clear difference in the atmosphere and mood of the students working on the questions in these two different groups. Students in the non-animation group struggled and voiced comments about how difficult the algorithm was. The animation group, conversely, appeared to be relatively more relaxed. The animation group's average time spent working on the questions was longer too, and longer time-on-task typically equates to better learning.

This study led us to speculate that one educational benefit of algorithm animations might be that they make challenging algorithms less intimidating and more approachable. Students who have algorithm animations available may be more likely to confront a difficult algorithm and spend more time trying to understand how it works. If so, this should lead to subsequent learning benefits. 
Studies such as this have begun to help educators better understand the potential value and utility of animations, but a great deal of work remains to be done. In particular, three areas of study need further research.

First, more empirical study must be performed to better understand how and why algorithm animations can assist learning. When and where should they be used? How should they look? For what algorithms should they be used? Second, researchers must develop a careful set of design guidelines and principles for the authors of algorithm animations. What are the features of a 'good' animation? What attributes should an algorithm animation include to maximally help students learn? Finally, new styles of interactive algorithm animation systems are needed that allow both instructors and students to directly manipulate the visual imagery representing the algorithm's structures and operations, and to play 'what-if' games on the algorithmic behavior. One can imagine an animation of a tree algorithm in which a student can be challenged to show how a particular operation rotates a subtree. The student should be able to interact with the visualization, manually perform the operation, then actually run an animation on a duplicate view to see if her prediction was correct.

I am convinced that as long as computer science is studied, understanding computer algorithms and data structures will be one of the most challenging but important aspects of the discipline. In the last 20 years, CS Education research on algorithm animation has made great strides, but we still have much work to do to better understand how this technology can truly aid students in learning about algorithms and gaining a deeper understanding of the fundamental principles of our field.

\section{DEVELOPING UNDERSTANDING FROM THE GROUND UP: CASE-BASED LEARNING (MARK GUZDIAL)}

There is a growing community of teacher-researchers in the general education community. These are researchers who study their own classes in a careful way, and publish their results to contribute to our knowledge about education. There are researchers in CS Education who use the same approach. It's particularly attractive for faculty who are interested in studying and improving their own teaching.

Much of the research that I and my students have done in CS Education has had this form. We don't typically use contemporaneous comparison classes. 
Rather, we gather similar data from classes over time, in order to compare the benefits of whatever changes we might be introducing into the class. We measure performance on isomorphic problems (similar structure, similar content, but constants or context changed). We use log file data to track process. We use surveys (sometimes standardized), interviews, and focus groups to study attitudes and motivations and to learn about students' intent in their process.

One of the studies that we did in this form was on how to teach the ModelView-Controller (MVC) paradigm better. MVC has always been hard for students to learn, as John Carroll and Mary Beth Rosson at IBM Watson Labs (Carroll, Singer, Bellamy, \& Alpert, 1990) and Randy Pausch (Pausch, Conway, \& DeLine, 1992), then at University of Virginia, found. However, it's important as most user interface toolkits are designed around an MVC structure. We used isomorphic problems on MVC on midterm examinations for three terms, while we varied the problems given, the style of lecture, and the kinds of activities we asked students to perform. The results were abysmal, with half the class not understanding the idea. We then developed a new approach, where we developed MVC, from scratch, in a live programming demonstration: First showing them how to build user interfaces without MVC, and then showing them how creating MVC-structured components helps to create better engineered interfaces. Performance on the same isomorphic problems jumped significantly that term (Guzdial, 2001). We have followed the course and found that the gains have remained through other changes and even a change of instructor in the course.

We have used the same teacher-researcher approach in studying technologies that we are developing. By trialing technologies in our own classes, we get a better understanding of how the technologies work and how classes should be tailored to best take advantage of the technologies. We can then go on to explain to other faculty what we did, and use our classes as examples.

One of the projects where we followed this approach was STABLE (SmallTalk Apprenticeship Based Learning Environment). STABLE was a case library of about a dozen projects, mostly good homework solutions by past students. Overall, there were some 1200 web pages for these dozen projects. These projects were presented in exceptionally detailed form:

- Each step of the project was presented at three or four levels of detail.

- All the classes of the project had their own page, with indices into the rest.

- Pages describing potential problems and repair strategies were provided. 
- Every project had multiple representations of the structure of the program and of the overall process of the project.

STABLE was used for several terms in a course on Smalltalk and objectoriented programming. Through tracking performance on isomorphic problems, both in assignments and in exams, we were able to find that STABLE impacted both programming performance on the homework as well as learning (about design, mostly - with little or no effect on learning about Smalltalk or other object concepts). However, students didn't like it. In surveys, interviews, and focus groups, they told us that STABLE was "badly structured" and "hard to navigate."

It took us another year of use to figure this one out, but with log file analysis by Colleen Kehoe, we finally did (Guzdial \& Kehoe, 1998). As the description above indicates, we provided an enormous number of resources for each project. But what Colleen found was that students almost never stayed within a single project. Instead, they were mostly comparing and contrasting between multiple projects, so our project-centered navigation (with no links between projects except from the top of the hierarchy) was completely wrong for their task.

The STABLE story points out that even teacher-researcher activity has the same fits and starts as does traditional research. Like more traditional research, teacher-researcher activity also raises more questions than it answers, but more informed questions than when we started. How should a case library be structured to support cross-case comparison? Why did the case library impact design learning, but not programming language learning?

The key to good teacher-researcher practice is also a key to good teaching activity overall: Collect data! Collect data on your practice. Invent new measurement instruments to find out what you need to know about what's working and what's not in your teaching. You will find that you are learning things that are not just about your practice, but about student learning in computer science overall. Publish that and help the rest of us learn what you're learning.

Computer science's ancestry in mathematics encourages us to emphasize logic over empiricism in our research. There's no need to go out and measure a few dozen triangles - we can simply think our way around all the issues of triangles. But students and learning are different. Students vary in far too many ways to simply think our way around them, and learning is not at all understood well enough to provide a simple mechanism for predicting how some intervention will work. The result is that we must collect data. 
We don't have a rich tradition of empirical research in computer science, as does psychology and education. So we borrow from them, and we invent some for ourselves. Don't let fears of insignificant statistical tests or too small a sample size prevent you from jumping in. The first goal of any research is insight - what's going on? Your results must only convince you that your insight is valid, not that it's applicable to everyone on the planet. Later, if you wish, you can work at improving the validity of your results. But first, collect data and try to make sense of it.

This is an important time to get involved in CS Education Research. We have all come to realize the important role that information technologies plays in our economy and our daily life. Funding agencies such as the National Science Foundation in the United States have come to realize that teaching more students better about information technology is critical to sustaining our economy in the long term. Yet, there are too few people studying how to do that teaching well. Be part of this important research effort, and start with your own students.

\section{RESEARCH INTO LOW-LEVEL MISCONCEPTIONS ABOUT PROGRAMMING (MICHAEL CLANCY)}

The previous two papers described current research in areas relating to computer science education. I will now review some older work, all of which investigates misconceptions or mistaken attitudes in students. To me, this is the most interesting and, for my teaching, the most relevant education research. It helps me interpret wrong answers - which I see a lot of! - and also guides me toward activities that address student problems.

\section{MISCONCEPTIONS}

\section{BUGGY}

I start with work not in computer science but in elementary mathematics, specifically, integer subtraction. Brown and Burton (1978) examined a data base of problems administered to Nicaraguan fourth, fifth, and sixth graders. From the data, they inferred a collection of buggy subtraction procedures, for example: 
"borrow from zero" - When borrowing from a column whose top digit is 0 , the student writes 9 , but does not continue borrowing from the column to the left of the 0 , e.g., $103-45=158$.

"smaller from larger" - The student subtracts the smaller digit in a column from the larger digit regardless of which one is on top, e.g., $253-118=145$.

Brown and Burton went on to build these rules into a program named BUGGY that simulated an errant student. Users of the program - Brown and Burton tested it both on student teachers and on seventh- and eighth-grade students - were required to identify the "student's" misconception. This exercise touched on several interesting pedagogical concerns cited in the article:

(Teacher training) "The realization that errors that appear 'random' are often the surface manifestations of a systematic underlying bug is a major conceptual breakthrough for many student teachers."

(Diagnosis) "In fact, there are a number of strategy bugs that teachers may have in forming hypotheses about a student's misconceptions.... [C]ommon strategy bugs are to jump too quickly to one hypothesis ... [and] to lock onto only one type of symptom."

(Vocabulary) "Even when one knows what the bug is in terms of being able to mimic it, how is one going to explain it to the student having problems?"

All the teachers found their experience with BUGGY valuable. So did the students; they acquired both a sensitivity to underlying causes of errors - both BUGGY's and their own! - and a language for talking about procedures, processes, bugs, and so forth.

\section{Davis: LISP Evaluation}

We move to programming misconceptions. Elizabeth Davis (Davis et al., 1993, 1995), working with others at Berkeley (where we have taught our introductory courses in LISP or Scheme since the late 1980s), conducted interviews with 36 novice programmers to explore their (mis-)understanding of the LISP evaluation process. 
She focused particularly on the roles of parentheses and quotes in expression evaluation. Students worked through exercises that involved producing a procedure call and evaluating the legality/effects of possible answers for a problem. Davis, like Brown and Burton, produced a number of buggy rules that students appeared to be following, for example:

"arguments grouped" - enclosing all arguments together in ( ) or ' ( ),

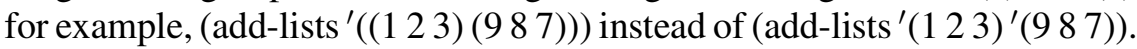

"lists unquoted" - failing to quote lists, for example, (add-lists (1 23 )

7)) instead of (add-lists '(l $\left.\begin{array}{llll}1 & 2 & 3\end{array}\right)^{\prime}\left(\begin{array}{lll}9 & 8 & 7\end{array}\right)$ ).

"quotes distributed" - using quotes inside of a list before each element instead of before the opening parenthesis of the list, for example, (add-lists (' 1 '2'3) ('9'8 $\left.{ }^{\prime} 7\right)$ ) instead of (add-lists' $\left(\begin{array}{lll}1 & 2 & 3\end{array}\right)^{\prime}\left(\begin{array}{lll}9 & 8 & 7\end{array}\right)$ ).

Davis went on to devise exercises to target these misconceptions, finding significant improvement as a result. These exercises were not uniformly successful; interestingly, she reports a small group of students who seemed unwilling to see consistencies in LISP interpretation.

\section{Recursion Studies}

There have been several studies of inaccurate models of recursion. Two of these are reported by Kahney (1992) and Dicheva and Close (1996). Kahney's work involved observing novice programmers designing recursive solutions in a LOGO-like data base manipulation language, and choosing a correct solution to a specified problem from several alternatives. He hypothesized various buggy models of recursion: the loop model, in which a recursive call is treated as a 'go to', plus several more primitive models. Dicheva and Close, working with 43 children between 10 and 14 using LOGO, found more detailed misconceptions involving both control flow and values of function variables and arguments.

\section{BELIEF AND ATTITUDE PROBLEMS}

\section{Fleury: Expert/Novice Beliefs about Programming}

Fleury (1993) focused on a different set of student errors, those produced by mistaken beliefs or attitudes. Fleury conducted in-depth interviews of 23 
students in introductory programming courses, along with four CS graduate students, all from the University of Wisconsin. Her key finding was that novices strove to avoid complexity, while experts aimed to manage complexity. Here are some examples of these differences:

(Reading code with data structures) "Some students expressed the belief that arrays and arrays of records made the programs containing them difficult for people to read. ... [Quote from student] S11: 'It looks like too much is happening, you know, when you first read the program. Oh, no! Arrays! Records! Everything else!' ... Experts, on the other hand, advocated the use of such data structures as arrays of records, and explained that they were expected as an alternative to freezing the program to work with a fixed number of individual variables." (Fleury, 1993, p. 359)

(Debugging) "Students see debugging as finding and fixing errors, with the emphasis on finding the errors.... Many students see debugging as essentially completed when they have found the procedure in which the (assumed single) error resides.... The experts viewed debugging and testing differently,... [explaining] that program comprehension is a necessary part of debugging and testing ... [and describing] the practical importance of fixing all the bugs." (Fleury, 1993, pp. 360-361)

(Maintenance) "Many students see program maintenance, modification, and extension as an academic exercises. They are concerned about minimizing typing and about facilitating superficial changes to program syntax.... Experts, on the other hand, assume that programs will be modified and extended over the course of the program lifetime in response to real-world events." (Fleury, 1993, p. 362)

\section{Guzdial: Design Bias}

Two other articles, one by Mark Guzdial and the other by Michael Eisenberg et al., report mistaken student beliefs about more focused programming concerns. Guzdial (1995) reported that students learning to program in Smalltalk display a centralized mindset, designing a single leader object that participates in all communications. He notes some consequences of this mindset:

"There is little real possibility of reuse here - all of the classes defined must be reused for exactly their original purpose, because all of the control 
and communications are centralized for a particular purpose.... Centralized models are efficient, easy to understand, and are often accurate depictions of a problem domain - in many situations, there is central control and global or leader-centered communication. However, as complexity increases, decentralized (distributed control, localized communication) approaches are more robust. A decentralized mindset leads to better understanding of decentralized phenomena and the creation of models that are more resistant to errors and change."

\section{Eisenberg et al.: Misperception of Procedures}

The work reported by Eisenberg et al. (1987) involved the study of 16 MIT students learning to program in Scheme. In Scheme, procedures are first-class; that is, they can not only be called, but can be passed as arguments to and returned as values from other procedures, as well as stored in data structures. For many students, a serious stumbling block to making use of these features was their more simplistic view of procedures as "active manipulators of passive data" and as "incomplete entities that needed 'additional parts' before they could be successfully used.... The focus on activity and incompleteness seemed to lead students to associate procedures more with the processes they describe rather than with the objects they are. Indeed, many students placed procedures in a category separate from other objects, viewing procedures as a different sort of thing - or, perhaps, not as a 'thing' at all."'

\section{THINGS TO BE LEARNED}

What can we learn from this research? One thing, as mentioned in the review of the BUGGY work, is an appropriate attitude about students' incorrect answers and what to do about them. If we are alert to the likelihood of misconceptions, we are more likely to regard wrong answers as opportunities to discover them. With a hypothesis about the causes of student errors, we can devise exercises to target them and to encourage students to reflect on their buggy procedures.

In addition, all these studies provide models for the budding educational researcher. Interviews and answers to detailed sets of exercises provided the raw data from which misconceptions were inferred. Instructors of large courses will have no trouble producing lots of data. In contrast, instructors of small classes may have the opportunity to work more closely with their students, teasing out their understanding of programming in interview-like sessions. Moreover, there are plenty of opportunities for such explorations, for example: 
syntax organization - what syntax errors are students learning a second language prone to, and why?

pointer errors - are they a result merely of losing track of details, of misapplication of some pattern learned in an earlier context, or of some misconception about the nature of a pointer?

concurrent programming - what models do students form, and what mistakes are they prone to?

library functions - what misunderstandings do students develop about data structures in a class library?

\section{COLLABORATION WITH EDUCATION DEPARTMENTS (NELL DALE)}

In most universities those of us who are interested in CS Education Research feel somewhat isolated; there are not very many of us within traditional CS departments. We, in the CS Department at the University of Texas at Austin, solved this problem by combining with the students in the College of Education and faculty in neighboring institutions to form a support group that has been a benefit to students and faculty alike. The seminar described here serves as a model for generating a community of those interested in CS Education Research.

About 11 years ago a group of faculty from the CS Department organized a seminar for faculty and students interested in CS Education Research. The impetus for this seminar was the Ph.D. program in CS Education offered in both Mathematics Education and in Science Education in the College of Education at UT Austin. The students in these programs were taking courses related to curriculum and research issues in either in math education or in science education but were getting little background in computer science curriculum issues or research methodology. Thus, we began by reviewing the various curriculum documents of the IEEE and the ACM. What began as a one-semester seminar has continued for 11 years.

We were, and are, a support group for those involved in CS Ed Research; we are not a group that conducts research projects. We have focused our attention on what is good research in computer science education, how success or failure can be evaluated, and how research results can make us better teachers. There is no reason why we could not conduct group research in the future, for ideas that have been generated as a result of group activities have lead individual group members to undertake parallel projects. Although the 
faculty members involved certainly support each other, our primary goal has been to support the graduate students.

Here are some of the activities that we do and have done:

As a group we review papers for conferences and journals. For example, each fall we take the SIGCSE and ITiCSE papers sent to use for review and ask each group member to review a subset of them. We discuss the papers and the reviews. A consensus review is then prepared and submitted. Seeing how others review the same paper is a learning experience for all of us, especially for the graduate students. This activity also gives us an opportunity to evaluate the research methodology of others.

We read and discuss articles that are of interest in the context of CS Education Research. We ask visiting faculty to share their expertise with us. We have staff from the Center for Teaching Effectiveness lead discussions on such topics as test construction and classroom management, which are not research related topics but are certainly valuable for future (and current) faculty.

As a group we prepared and submitted a grant proposal to the NSF Faculty Enhancement Initiative. When the grant was funded, the entire group, both faculty and graduate students, participated in recruiting participants, organizing the workshops, presenting material, acting as lab TAs, and participating in the evaluation and dissemination aspects of the proposal. Friendships formed between the faculty participants and the graduate students (now faculty themselves) have continued to flourish.

But the most important role of the group is to give the graduate students input and support in their dissertation research. The graduate students give regular status reports, circulate drafts for feedback, and practice their talks before the group.

Last but not least, the group parties together. At the end of each semester, we meet for lunch. Old group members join us to share their experiences, pictures of their children, and offer encouragement to those not yet graduated.

\section{CS EDUCATION RESEARCH: FINDING A COMMUNITY (SALLY FINCHER)}

As educators, we all have a professional interest in the teaching that we deliver and the quality of learning that takes place in our students. We write lectures, devise activities and create assessments. At the same time institutions have 
quality assurance mechanisms - student evaluation questionnaires, periodic reviews, external examiners - which address the standard of our provision. This is part and parcel of the normal business of being a lecturer.

When interest goes beyond the individual classroom, to examine the efficacy of specific approaches or techniques, to judge the generalisability or transferability of outcomes, to work to understand whether there are a set of conditions or abilities that pre-dispose for success in CS, then we move towards "Computer Science Education Research."

Crucial to success in this area is the location not only of good, relevant, literature (see Mike Clancy's paper in this same set) but also of an active community of practice. The new researcher needs to be able to participate in discussion and debate in order to contribute to discourse which defines and refines the thinking in this field. But how can this community be found? And how can a new research find a "way in"?

\section{FINDING YOUR CSED COMMUNITY}

There has been considerable interest over the years in what forms a 'community' (Agrè, 2000a; Cohen, 1985; Wenger, 1998) and what characterizes a 'research community' in particular (Becher, 1989; Crane, 1972). Research communities are often well-defined by their participants: by their institutional affiliation (somewhere that is 'known' for doing work in a particular field), by their individual status (someone is 'known' as being a leader in the area, whose work is seminal, and who attracts new postgraduates entering the field) and by their boundaries ('social anthropology,' for example, is recognizably different from 'anthropology', and sharply distinguished so by the researchers who work and publish in that area). Additionally, research communities are characterized by the formal frameworks of their dissemination - workshops, mailing lists, subject-specific conferences, journals, etc.

However, this characterization is problematic for Computer Science Education Research. Because this is an emergent research area the status of participants is not always obvious. There are no 'centres', neither institutional nor individual; there is hardly anyone for whom this is their only research activity, or even their primary one, indeed the 'leading lights' are often better known for their work in other areas. Not only are the boundaries of the community hard to identify, so are the boundaries of the 'discipline' itself which is particularly susceptible to what Phil Agre has characterized as 
'anamorphism and overlap' (Agre, 2000b). Anamorphosis is a phenomenon of distortion, where the relationships between things are more-or-less preserved but their relative importance is distorted by the position of the observer. One of the most famous visual examples of this is Saul Steinberg's View of the World from Ninth Avenue which appeared as the cover of the New Yorker, 29th March 1976, where there is a lot of detail of Manhattan, but the further away from that, the hazier the details become (so that the Pacific Ocean is just a name - something that the viewer knows is 'over there' but is of no importance). In a similar way, I have a map which has lots of detail of my classroom, my department, my institution, my research; the farther away from that, the hazier my map becomes. This problem of anamorphosis is compounded by the fact that we all have such maps. Fortunately though, we don't live in different worlds, and most things will appear on everyone's map. Then research (and research discourse) can be viewed as identifying the places where our maps overlap, by productively enlarging our understanding through discussion and the investigation of our different areas of detail.

If it is difficult to know who's 'in' the community, difficult to know where the edges of the community are, and difficult to know where the knowledge areas overlap, then it is probably easier for those entering the field to find a 'way in' via the more formal frameworks of communication and dissemination. There are several publications and events which have a CS Education Research component, and thus overlap into our area of interest. Where to find them (and which to choose) rests on a matter of subject area and a matter of temperament and methodology.

\section{Subject Area}

With regard to subject area, there are four broad areas, each characterized by a different emphasis:

- Small-scale investigations of a single aspect of discipline or practice. These are often found at SIGCSE-sponsored conferences: the annual SIGCSE (ACM Special Interest Group Computer Science Education) Symposium, Innovation and Technology in Computer Science Education conference (ITiCSE), and Australian Computing Education conference (ACE) (www.acm.com/sigs/sigcse)

- Investigations of specific mental \& conceptual skills is often found at Psychology of Programming Interest Group (PPIG) workshops and mailing 
list (www.ppig.org), and in Empirical Studies of Programmers workshops (ESP)

- Investigations based within the educational tradition are concentrated within educational conferences, for example the British Educational Research Association (BERA) (www.bera.ac.uk), and the American Educational Research Association (AERA) (www.aera.net)

- Investigations motivated by the use of tools in CS teaching and learning, an especially good place to look for this is the newly-founded on-line Journal on Educational Resources in Computing JERIC (http://fox.cs.vt.edu/ JERIC/), and the occasional visualisation workshops (such as: http:// cs.joensuu.fi/pages/pvw/workshop.htm)

\section{Temperament and Methodology}

Subject area, though, is not the only way to characterize these different activities, and it may be more useful to think about what kind of researcher you are, and what kind of research approach these same activities typify:

- SIGCSE-sponsored conferences often feature practitioner research, and 'action research' approaches

- ESP and PPIG overlap with psychology and often (but not exclusively) apply the quantitative and statistical methodological approaches which are common in that disciplinary area

- BERA, AERA (and similar conferences where CSEd overlaps with education) are often theoretically motivated, that is they apply educational theory to CSEd situations and material.

- JERIC, and other activities like it are technology-driven - 10 years ago much work was done with Hypercard or similar systems, now the leading technology is the Web and there is a great focus on it, although some earlier work, of course, generalizes and transfers to the new technologies.

The dissemination channels described here are not the only ones, of course. There are several organisations in cognate disciplines which have overlapping elements - for example, the IEEE CS-society sponsored Frontiers in Education conference, the American Society of Engineering Education (ASEE), Société Européene pour la Formation des Ingénieurs (SEFI) and International Federation for Information Processing (IFIP) Working Group 3.2: Informatics Education at the University Level. 


\section{THE WORK OF BELONGING}

There are but few places specifically devoted to CSEd research. A CSEd Doctoral Consortium is held every year at the SIGCSE symposium and there are three mailing lists: csed-research (csed-research@acm.org) csergi (CS Education Research Groups International: csergi-list@ukc.ac.uk) and csern (CS Education Research Network: http://groups.yahoo.com/group/csern).

Knowing that a relevant community of interest exists is not enough. Almost all the resources listed here can be approached passively; conference proceedings and journals can be read, mailing lists can be lurked on. However, to realize the benefits, we have to join in. This is what Etienne Wenger (Wenger, 1998) calls "the work of belonging" and involves identifying and approaching others who work in a similar area, or in an area or with an approach sympathetic to our own. These skills are well described elsewhere (Agre, 2001) but all involve active engagement. Discussion and debate help to form a community; publication to define it.

\section{REFERENCES}

Agre, P. (2000a). Commodity and Community: Institutional design for the networked university. Los Angeles: University of California.

Agre, P. (2000b). RRE notes and recommendations. Los Angeles: University of California.

Agre, P. (2001). Networking on the network. Los Angeles: University of California.

Becher, T. (1989). Academic tribes and territories: Intellectual enquiry and the culture of disciplines. Milton Keynes: Open University Press.

Brown, J.S., \& Burton, R.R. (1978). Diagnostic models for procedural bugs in basic mathematical skills. Cognitive Science, 2, 155-192.

Carroll, J.M., Singer, J.A., Bellamy, R.K.E., \& Alpert, S.R. (1990). A view matcher for learning smalltalk. In J.C. Chew and J. Whiteside, (Eds.), Proceedings of CHI '90: Human Factors in Computing Systems (pp. 431-437).

Cohen, A. (1985). The symbolic construction of community. Chichester: Ellis Horwood.

Crane, D. (1972). Invisible Colleges: Diffusion of knowledge in scientific communities. Chicago: University of Chicago Press.

Davis, E., et al. (1993). Mind your p's and q's: Using Parentheses and Quotes in lisp. In C. Cook et al. (Eds.), Proceedings of the fifth Workshop of Empirical Studies of Programmers, Ablex.

Davis, E., et al. (1995). Learning to use parentheses and quotes in LISP. Computer Science Education, 6 .

Dicheva, D., \& Close, J. (1996). Mental models of recursion. Journal of Educational Computing Research, 14. 
Eisenberg, M., et al. (1987). Understanding procedures as objects. In Proceedings of the Second Workshop of Empirical Studies of Programmers, Ablex.

Fleury, A. (1993). Student beliefs about Pascal programming. Journal of Educational Computing Research, 9.

Guzdial, M. (1995). Centralized mindset: A student problem with object-oriented programming. Proceeding of 26th SIGCSE symposium on Computer Science Education, SIGCSE Bulletin, 27, March 1995.

Guzdial, M., \& Kehoe, C. (1998): Apprenticeship-based learning environments: A principled approach to providing software-realized scaffolding through hypermedia. Journal of Interactive Learning Research, 9, 289-336.

Guzdial, M. (2001). Using Squeak for Teaching User Interface Software. In Proceedings of ACM SIG Computer Science Education Conference (pp. 291-223). ACM: Charlotte, NC.

Houndhausen, C.D., Douglas, S.A., \& Stasko, J.T. (Submitted for publication). A meta-study of algorithm visualization effectiveness.

Kahney, H. (1992). Some Pitfalls in Learning About Recursion. In Marc Eisenstadt et al. (Eds.), Novice programming environments: Explorations in human-computer interaction and artificial intelligence, LEA.

Kehoe, C., Stasko, J., \& Taylor, A. (2001). Rethinking of the evaluation of algorithm animations as learning aids: An observational Study. International Journal of Human-Computer Studies, 54, 254-284.

Pausch, R., Conway, M., \& DeLine, R. (1992). Lessons learned from SUIT, the Simple User Interface Toolkit. ACM Transactions on Information Systems, 10, 320-344.

Stasko, J., Domingue, J., Brown, M.H., \& Price, B. (Eds.). Software Visualization: Programming as a multimedia experience. MIT Press: Cambridge, MA.

Wenger, E. (1998). Communities of practice: Learning, meaning, and identity. Cambridge: Cambridge University Press. 